\title{
Using biographical narrative interviewing methodology to research adults' experiences of disclosing childhood sexual abuse
}

\author{
Joseph Mooney
}

\begin{abstract}
Disclosure of sexual abuse can be a process rife with barriers, setbacks and trauma. Those who have experienced sexual abuse in childhood tend to delay disclosure, possibly until adulthood, and can be silenced by structural, societal and personal barriers. Those who do disclose are often referred to as the 'tip of the iceberg', highlighting the potentially large hidden population who never come forward. This paper is drawn from a wider study which presented narratives of adults who have disclosed their experiences of childhood sexual abuse to social work services in the Republic of Ireland. In Irish child protection policy such disclosures are called 'retrospective disclosures'. Recent reports by Irish State bodies have shown that those who have reported their childhood experiences to child protection authorities have not always received the response they would have hoped for (Office of the Ombudsman, 2017; Health Information and Quality Authority, 2016). Since the 'narrative turn' in social work research a rich body of work has been produced which explores the use of narrative approaches to address pertinent issues affecting social work practice. Biographical Narrative Interviewing Methodology (BNIM) is one such approach to narrative research and focuses on the presentation of voice and life experience. This paper presents the BNIM data collection process as it was used in the wider study and justifies the rationale for using such a methodology as a means of conducting research on a sensitive topic with a population that are too often silenced. This paper presents how an awareness of the socially constructed environment, the dynamics of abuse and the use of appropriate methodologies can bring such silenced and marginalised voices to the fore.
\end{abstract}

Keywords: child sexual abuse; narrative research; social work; adult disclosures; child protection

1. Assistant Professor of Social Work, School of Social Policy, Social Work and Social Justice, University College Dublin

Address for correspondence: joseph.mooneyl@ucd.ie

Date of first (online) publication: 15th September 2020 


\section{Introduction}

The Dublin Rape Crisis Centre's Sexual Abuse and Violence in Ireland (SAVI) Report (McGee, Garavan, de Barra, Byrne, and Conroy,2002) highlighted that $42 \%$ of women and $28 \%$ of men have experienced some form of sexual abuse during their lifetime. One of the more striking statistics presented by this report reveals that of the 3,120 participants surveyed almost half (47\%) had never previously disclosed their experiences prior to being asked about them in the research interview. This statistic hints at the potential size of the hidden population who have been affected by sexual abuse in childhood; those silenced by its power and control. Disclosure of sexual abuse is a life-long process fraught with many barriers; societal, structural, inter-personal and ontogenic (Alaggia, 2004; Hunter 2010, 2011; Collin-Vézina, Sablonni, Palmer and Milne (2015). Most delay disclosure, many until adulthood with an unknown proportion who never tell. This paper is drawn from a wider study of adult's who have experienced sexual abuse in childhood and who have reported these experiences to child protection services in the republic of Ireland. Child protection policy in Ireland tasks the Child and family Agency with the role of assessing and responding to, not only disclosures by children, but also those made by adults. Ireland is somewhat unique in this respect as it channels adults into a child protection system. Such disclosures are called retrospective disclosures in Irish child protection policy and the State's response to these has been variable and inconsistent over the past two decades leading to further silencing and repetition of the dynamics of abuse itself such as belief, lack of trust, shame and stigma, to name but a few (Health Information and Quality Authority (HIQA), 2016; Office of the Ombudsman, 2017; Mooney, 2014). A former CEO of the State child protection service is quoted as saying that retrospective disclosures have been 'one of the major challenges facing us since we were set up as an agency' (RTE's This Week, 30th July 2017). This paper focusses on the structural and personal barriers that silence such a population and cast shadow over them as individuals and in some case over their very experiences. The paper highlights the author's use of Biographical Narrative Interview methodology (BNIM) to cast light on this often-hidden population and their experiences.

\section{Context}

Child protection social workers in Ireland, operating within the Child and Family Agency (Tusla) are obliged under Irish national child protection guidelines, Children First (Department of Children and Youth Affairs, 2017) to receive and assess retrospective reports from adults concerning abuse they experienced as children. Tusla are the national statutory agency with responsibility for child protection and 
welfare, and associated areas, within the Republic of Ireland. Their remit extends to assessment and management of adult disclosures of childhood sexual abuse in instances where an alleged perpetrator may continue to pose a risk to children. A retrospective disclosure is defined as disclosure made by and adult (over the age of 18) of abuse they experienced as a child. Previous studies in Ireland have found inconsistent and variable adherence by child protection social workers to child protection guidelines (Department of Health and Children, 2008; Ombudsman for Children's Office, 2010). While these previous assessments examined adherence to child protection guidelines in a general sense, Mooney (2014) established, albeit with a small non-generalisable sample, that these inconsistencies and variable practices also exist in relation to the specific child protection function of receiving and assessing adult disclosures of childhood sexual abuse or 'retrospective disclosures' (Mooney, 2014). This was also echoed in a review conducted by the Health Information and Quality Authority(2016) who are an independent body charged with investigating health and social care services in respect of their adherence to national guidelines and best practice.

This paper is drawn from a wider study which examined the experiences of those adults who come forward to make disclosures to child protection social workers. The paper therefore presents exploratory research in to a particularly under-researched area. Given the dynamics and long-lasting psychological and socio-ecological effects created by an experience of childhood sexual abuse (see Browne and Finkelhor, 1986; Freeman and Morris, 2001; Barrett, Kamiya and O'Sullivan, 2014), alongside the multiple barriers and obstacles involved in disclosure, those who experience abuse can often be silenced or find it difficult to come forward. It should be noted at this point that experiences of abuse cannot be generalised and while silencing through family dynamics, fear, threat or social taboo is commonly reported it is not a universal experience. Many survivors and victims find strength in their voice and either through their own resilience or supportive networks, go on to advocate and speak out about their experiences. The wider study upon which this paper is drawn examined what is it like for an adult to disclose such an experience to child protection social work services in the Republic of Ireland. This biographical narrative research was conducted with five adults who have experienced childhood sexual abuse and who have engaged with social work services to disclose their experiences. The findings of the research show predominantly negative experiences with many of the adults regretting their decisions to engage and some being significantly negatively impacted by the responses they received. The findings also reveal wider structural issues within the system itself with deficits in law, policy and practice all impacting upon the adult coming forward. This paper presents how using narrative research techniques we can access and learn from these voices. 


\section{What casts the shadow?}

The issue of child sexual abuse has a long history of regression and emergence within the public consciousness (Olafson, Corwin, and Summit, 1993); with research since the 1960s and 1970s establishing that much of child sexual abuse occurs either within the immediate nuclear family or within wider extended family and social structures and, in an Irish context, child sexual abuse being referenced in early Irish Brehon Laws as well as by St. Columbanus in the 6th Century (Lalor, 1998; McGee, Garavan, de Barra, Byrne, and Conroy, 2002; McGee, Garavan, Leigh, Ellis, and Conroy, 2005; Douglas and Finkelhor, 2005). However, taking note of media coverage, judicial pronouncements and political concern, it is easy for society to form the mistaken belief that child sexual abuse is a recent phenomenon. It has also been easy for society, in various countries, to link child sexual abuse almost exclusively with the Catholic Church, State Institutions and, more recently, celebrity culture given the levels of media and public attention. Finkelhor, going some way towards explaining the lack of public awareness of child sexual abuse in previous years notes that low rates of child sexual abuse and thereby low awareness of the issue in some countries 'may be due to social environments where candid disclosures of sexual behaviour are still very problematic' (1994, p.411). Ferguson and Kenny (1995), specifically referencing Ireland, reinforce this element when they suggests that in a traditional order characterised by cultural denial, patriarchal social relations and repression, sexual abuse was not classified and worked with in practice' (Ferguson and Kenny, 1995, p.31).

Specific shadows are cast over the issue in Ireland due to a particular cultural and religious backdrop. The taboo surrounding sex and family life, not to mention child sexual abuse, developed through an environment of repression and silence that is only beginning to be broken down. Victorian commentators tended to discuss child abuse in terms of incest, overcrowding, poverty, moral character and a phenomenon of lower class families (Olafson et al., 1993; Buckley, 2013). 'Incest was spoken of euphemistically in medical journals as 'things done in secret" (Buckley (2013) p.153) and this euphemism or taboo pervaded in Ireland well in to recent times and in some sense still exists. O'Sullivan highlights examples of knowledge of sexual abuse within reformatories in the 1970s not being reported by those who ran the institutions because 'child sexual abuse' had not been 'coined' (2002, p.198). Repressive and conservative attitudes towards sexuality, morality and the role of the family in Irish society, all influenced significantly by the teachings of the Catholic Church, were the dominant discourses and knowledges within the field at the time and they shaped public opinion and policy in relation to child sexual abuse and its surrounding issues. Michel Foucault, particularly in his writings on 'the confessional' (1976), explains the development of such a taboo as an 'injunction to silence' and describes it in the sense of hear no evil, speak no evil, see no evil; '... an injunction to silence, an affirmation of non-existence, and, by implication, an admission that 
there was nothing to say about such things, nothing to see and nothing to know' (Foucault, 1976, p.4). Although the taboo surrounding sexual abuse may be fading in modern times, 'veiled issues still prevent victims from reaching out to authorities to reveal the abuse they suffer' (Collin-Vézina, De La Sablonniére-Griffin, Palmer and Milne, 2015, p.131).

It is these socially constructed perceptions of child abuse that have led to the creation of certain knowledges and discourses about children and abuse, about child abusers and about child abuse itself. It is important, if not imperative, for researchers in this field to be aware of how these knowledges are created and how dominant discourses have the power to shape knowledge and interpretation of a given matter, and potentially silence those who don't 'fit' within such discourses. Olafson et al (1993) discuss these issues in terms of the 'emergence and regression' of child sexual abuse; not the phenomenon itself, but crucially, our awareness and knowledge of it. They highlight their thesis using the work of Sigmund Freud as an example of such emergence and regression. Freud's early work could be viewed as visionary in terms of its capacity to stand up alongside contemporary research relating to child sexual abuse. Olafson et al (1993) suggest that Freud had established that experiences of sexual abuse are reluctantly recalled by victims, that a majority of abuse is committed within the family and that females are the predominant victims of such abuse (see also Masson, 1984; Azzopardi, Alaggia and Fallon, 2017). Freud however retracted his earlier theories in respect of child sexual abuse due in part to Victorian outcry and also in favour of his theory of psychoanalysis. 'I believed these stories, and consequently supposed that I had discovered the roots of the subsequent neurosis in these experiences of sexual seduction in childhood ... if the reader feels inclined to shake his head at my credulity, I cannot altogether blame him' (Olafson et al, 1993, p.11). This retraction by Freud had the effect of placing a question mark over the effects and very existence of the phenomenon of child sexual abuse within the dominant discourse. 'Most reports of sexual abuse were, therefore, reframed as being motivated by children's wishful fantasies for sexual attention' (Azzopardi et al, 2017, p.2). An effect which has continued to over-shadow those effected, causing problematic dynamics in relation to disclosure, belief, trust, shame and guilt and issues for society and researchers in relation to prevalence, impact and access to this often-silent population (Rush, 1996).

Our knowledge and awareness of child sexual abuse is partly based upon those who disclose. In the field of child sexual abuse scholarship, the word 'disclosure' continues to be used in numerous ways to describe varying scenarios. Disclosure has been defined as the act of informing or telling someone about the abuse, formally or informally, making a statement to the authorities, or making something known that was secret (Jones, 2000; Campbell, Greeson, Fehler-Cabral, and Kennedy, 2015; Ulman, Ming-Foynes, and Tang, 2010). Alaggia's typology of disclosure tells us that disclosure occurs in many different ways such as purposively telling, accidental, elicited, behavioural, purposefully withheld or triggered (Alaggia, 2004). Disclosure is a sensitive, dialogical, inter-relational and fluid process that begins at the time 
of the abuse. During the process of disclosure many dynamics and factors interact, such as secrecy, power, blame, guilt, belief, trust and fear of negative consequences (Collin Vézina, Daigneault and Hébert, 2013; Campbell et al, 2015; Hunter 2010, 2011; Alaggia et al, 2017).

The barriers that impede a person from disclosing are variable and individual to the person affected. However, there are some common barriers which are established in the research. Gender, whether of victim or offender, can play a significant role in choosing to come forward. Alaggia (2005) found that males withheld due to a fear of being stigmatised as a 'victim', with stereotypes surrounding masculinity also playing a significant role (Dorahy and Clearwater, 2012). Females commonly reported that issues regarding blame and belief would come in to play if they disclosed with women 'recounting this fear as over-riding their decision to tell (Alaggia, 2005, p.463). Delay in disclosure is a common occurrence with approximately $60 \%$ delaying for five years or more (Hébert, Tourigny, Cyr, McDuff, and Joly, 2009; Alaggia, 2005). The barriers recognised as causing such delays are the 'closeness to the perpetrator, multiple perpetrators, age at onset, and severe abuse' (Jonzon and Lindblad, 2004). Delayed disclosure has also been linked to repressed, recovered or delayed memories and the wider research project upon which this paper is drawn echoes this.

Family dynamics are among the most prominent barriers to disclosure given that a majority of abuse is experienced within the individual's familial and smaller social circle (Leventhal, 2001). Irish research suggests that $76 \%$ of females and $80 \%$ of males know their abuser (McGee et al, 2002). In addition to the closeness to the perpetrator, as mentioned above, factors such as power, trust and loyalty can all play a prohibitive role (Mian, Wehrspann, Klajner-Diamond, Labaron, and Winder, 1986; Reitsema and Grietens, 2016; Anderson, 2016). Alaggia and Kishenbaum (2005) identified a number of family dynamics which impede disclosure and silence those affected; rigidly-fixed, patriarchy-based gender roles in the family; the presence of family violence; closed, indirect communication and, finally, social isolation (2005). Critically, they also highlight the potential 'cultural silence' that may impact upon an individual's ability to disclose. Tener and Murphy (2015) highlight that 'whether to disclose or not' is a decision that must be negotiated by an individual each time the they are presented with a new situation; whether that be an encounter with a social work service or a researcher. Creating safe and supportive environments that encourage and facilitate disclosure is key to preventing further trauma for those affected. However, in addition to, and in part because of, the socially constructed nature of our responses to child sexual abuse, disclosure itself continues to be a phenomenon laden with pitfalls, obstacles and barriers; a veritable gauntlet for those impact by sexual abuse in childhood.

Reactions to disclosure, interpersonal or societal, can also be critical in determining the extent of on-going trauma, the decision to tell again at a future time or the decision to stay silent. Research shows that most individuals who experience childhood sexual abuse do not disclose until adulthood (McElvaney, 2013; McNulty 
and Wardle, 1994, p.553) with, what is a potential large proportion, not disclosing at all (McGee et al, 2002). Disclosure is also influenced by the life-course trajectory, with more informal disclosures in childhood and adolescences to more formal disclosure in adulthood. Professionals should therefore be prepared for disclosures of child sexual abuse by adults (Alaggia, Collin-Vézina and Lateef, 2017) and should expect that such a disclosure is not the first made by such an individual (Alaggia, 2004) but that this does not detract from its significance, either to the individual or in terms of child protection. Alaggia goes onto highlight that even if an individual has disclosed before it is important to "bear in mind that passage of time does not necessarily mitigate the negative effects of child sexual abuse' (Alaggia, 2004, p.1222-1223). Furthermore, when it comes to disclosing to a professional service, such as child protection services, there may be greater expectations in relation to receiving an appropriate response and therefore an inappropriate response at this level, as this paper presents, can in some instances lead to high levels of frustration, confusion and potential re-traumatisation and re-victimisation for the adult who decides to come forward and silencing those yet to do so (Denov, 2004; Hooper and Warwick, 2006).

Given the significance of the dialogical and inter-relational aspects of disclosure as well as the importance of the reaction and response to disclosure the process of researching such an issue is rife with ethical and methodological dilemmas. It is also a process that places a heavy responsibility upon the researcher to do no harm in terms of their response or reaction to the data received. It is therefore important for individuals who have experienced childhood sexual abuse, professionals and researchers working in this area and society at large to have greater knowledge about what present as facilitators and barriers to making such disclosures. 'Having a better understanding of the process and of the factors that influence disclosure may favour practices that are more responsive to survivor's needs' (Collin-Vézina et al, 2015, p1.32).

Breaking the silence presents multiple barriers across a person's lifecourse. These barriers range from macro level structural and societal barriers to micro level personal and inter-personal factors all of which are influenced by various power dynamics such as the power of the abuse itself to silence, the power of dominant societal discourses to 'other' and the power of personal reaction and responses to traumatise and re-traumatise. The wider study establishes that it is imperative that social work practitioners are cognisant of such factors when receiving disclosures from those affected. But it is also imperative that researchers in the field are as equally aware of such dynamics that may be at play so that risk of re-traumatisation is reduced. Jerry Tew, a social work scholar, states that 'before embarking on strategies in support of emancipation, it may be important to acknowledge the degree to which groups and individuals may have come to experience powerlessness, often in quite extreme forms' (2006, p.42). Tew suggests that 'invitations to co-operate and work alongside may potentially allow shifts from entrenched identities (such as 'expert' or 
'victim') and start to undermine social constructions of 'us' and 'them" (2006, p.43). Foucault's earlier theorisation of power presents it as an inter-relational process and that power is imminent in our relationships. Given the added power and control dynamics at play in an experience of abuse and subsequent attempts to disclose it is imperative that cognisance is paid to the element of power in any attempts to reach populations hidden or silenced by abuse. 'Power lurks in all our reflections and decisions. Just figuring out who gets the privilege of making meaning is laden with issues of power' (Potts and Brown, 2003, p273)

\section{Access and methodology}

The wider study was exploratory in nature and concerned an area that experiences a dearth of academic attention. The author assumed the view that, because so many aspects of the subject matter are socially, politically and culturally mediated, in order to capture the experiences of disclosure by those who have been abused required a methodology that would allow the participant's voice to speak for itself. Biographical Narrative Interviewing Methodology (BNIM) was specifically chosen due to its focus on understanding 'somebody's experiencing of something' (Wengraf, 2017, p15). The methodology was also suited to the author's own professional background as a social work practitioner in that social work practice frequently draws upon narrative approaches when working with service users (Fraser, 2004). This was also complimentary to the overarching aims of the study which were to examine adult's interactions with social work services when disclosing childhood abuse. As highlighted by Kohler, Riesmann and Quinney 'a central area of narrative study is human interaction in relationships - the daily stuff of social work' (2005, p.392). While sections of Irish national child protection policy seek to address the various complex issues affecting those who have experienced childhood sexual abuse, the voices of adults who have experienced childhood sexual abuse is currently absent from such policy (Mooney, 2014).

Due to the sensitive nature of the research topic it was not feasible to sample participants from the general population. The main reason for this was the inability to provide adequate support services to members of the general public. The sample included in the wider study were accessed via an agency called One in Four who offer services to adults affected by sexual abuse in childhood. One of the key reasons for this was the organisation's capacity to act as gate-keeper and to recruit participants who they felt were able to participate in this study and to whom they could provide follow up supportive services where necessary. The eventual participants had already received therapeutic input in respect of their experiences of abuse and were supported through the experience of disclosing to a social work service by an advocate.. They were therefore a sample who had already told someone about their abuse and due 
to this potentially had additional skills, language and understanding in respect of their abusive experience. One in Four recruited five participants in line with the researcher's inclusion and exclusion criteria and the final sample included four males and one female.

\section{Biographical Narrative Interviewing Methodology (BNIM)}

Biographical Narrative Interviewing Methodology is a form of qualitative data collection and analysis. It originated from a narrative biographical method which was used in a study conducting in the 1970s which was examining the experiences of Holocaust survivors (Fischer-Rosenthal and Rosenthal, 1997) and is useful in encouraging stories or narratives from the lives of those interviewed (Wengraf, 2001). It therefore has its origins in collecting sensitive and hard to reach data. It can be used to gather data relating to whole life histories or parts of life (Corbally \& O'Neill, 2014, p.35). BNIM gathers rich qualitative data and therefore collection and analysis of data from a large sample is neither feasible nor recommended (Jones, 2003). The sample size for the wider study therefore consisted of 5 participants. This sample is representative of studies that apply BNIM and similar narrative methodologies (Bradley, 2014; Corbally \& O'Neill, 2014). The methodology itself has two main components; data collection and data analysis. It is possible to use the BNIM data collection process to gather data later to be analysed using a different methodology but the use of the BNIM analysis is only feasible with BNIM data (Corbally \& O'Neill, 2014; Wengraf, 2001). The wider research project used both BNIM data collection and BNIM data analyses stages on one interview while using an alternative, thematic analysis, for the remaining four interviews.

The BNIM data collection method is composed of three Sub-sessions. The first of these is the use of a SQUIN (Single Question Used to Induce Narrative) (Wengraf, 2001; Wengraf, 2017). A SQUIN is a single, carefully designed question used to prompt the interviewee to provide a free narrative relating to the topic of the SQUIN. During an interviewee's response the researcher must not interfere by use of prompts, direction or questioning. This relinquishing of control by the researcher makes the SQUIN a powerful methodological tool for breaking silence and creating a platform for individual voice and lived experience. "Eliciting open-ended narratives provides a window on the very structure of individual's representations...stories allow researchers to see the Gestalt - the interrelations of structural linkages that individuals perceive among positive and negative attributes and experiences' (Murray, 1994, p.660). The process therefore presented participants with an opportunity to explore their own experiences of the positives and negatives of disclosing to child protection social work services and to present that in an un-interrupted narrative. The obvious risk with this approach is that a participant could chose to speak about 
whatever they wish, go off topic or avoid the research question due to discomfort or avoidance. A carefully designed SQUIN seeks to limit this possibility by broaching the research topic but not be prescriptive in requiring certain data or a certain response. The SQUIN used in the wider project was as follows:

As you will know from the information about the study I am researching adult's experiences of disclosing or referring childhood sexual abuse to social work services. I'm interested in what it is like for an adult who has experienced childhood sexual abuse to refer that experience, or those experiences, to a child protection social worker. I'd like to hear your story of that experience. You can start at whatever point you wish, I won't interrupt or say anything throughout and will only listen and take some brief notes for some follow up questions later.

While the role of the interviewer in an official disclosure capacity can impact on the level and depth of disclosure (McElvaney, 2013), similar concerns exist around conducting research (in this sensitive area of social work practice) with adult survivors of abuse on their experiences of disclosure. Similar to the importance of a response to a disclosure a critical part of receiving the response to the SQUIN is being aware of your own and the interviewee's emotional state, recognising this and taking time out of the interview process to manage this if needed (Wengraf, 2017). The 'as much or as little' option allowed participants to discuss their individual experiences of abuse if they so wished but without any obligation or direction to do so. Most participants chose not to do so with one participant reflecting on this feature of the interview as a comforting element:

Coming forward to someone is a massive, massive thing to do. It's a massive thing to do and even like speaking to you today I don't have to go in to details about you know, and it's some relief that you know I don't have to go into details of my experience of sexual abuse. But even then, it's still a little a bit, probably I was a little bit anxious coming in. (Alan)

Once the participant has exhausted their initial free-narrative, the researcher is permitted to move to the second stage of the methodology. A short interlude is provided where the researcher has an opportunity to reflect on the free-narrative and any notes taken and formulate some questions that aim to elicit further, detailed narratives on points of interest to the researcher. Power is retained somewhat by interviewee in that such questions must be posed using the participant's own words and language and based upon what they said. The methodology also seeks to protect the flow of the initial narrative in that the questions must also be posed in the order in which they arose in the initial narrative (Wengraf, 2001; Bradley, 2014). Given the sensitive and often hidden nature of the population under study this 'protection' of the participant's personal narrative was a significant factor in the selection of this 
methodology. The potential structural, personal and inter-personal barriers, power dynamics and issues regarding trust and belief, as discussed above, necessitated the use of a methodology that could be sensitive to such dynamics and create a platform for such often hidden voices. BNIM requires the researcher to 'for as long as possible give up control refuse to take up offers of partial control and maintain the maximum of power-asymmetry' (Wengraf, 2001, p.113; See also Rosenthal, 2003). 'This very shift encompasses a willingness on the part of the researcher to cede 'control' of the interview scene to the interviewee and assume the posture of active listener/audience participant' (Jones, 2003, p.62); thereby respecting individual voice and experience.

The methodology allows for use of sub-session one and two without resort to, what is commonly referred to as an optional, sub-session three (Wengraf, 2001; Wengraf, 2017). The third stage, or third sub-session, allows the researcher/interviewer to pose unstructured questions regarding issues of interest in respect of the research question that may not have arisen in the narrative. This sub-session was not utilised in the wider study as it was felt that it countered the efforts in sub-sessions one and two to gather the interviewee's narrative with as little interference or influence as possible. Given the potentially sensitive nature of researching issues surrounding child sexual abuse and the often commonly present dynamics of power and control this research sought to focus solely on what the participant chose to share in the words they used to do so.

BNIM is strict in respect to how data is collected but more mailable in respect of how data are analysed. The full BNIM data analysis process includes the use of an interpretive panel. The panel serves as a safeguard by which 'to overcome the distorting effects of the blindspots and the hotspots, the defended subjectivity' of the researcher (Wengraf, 2001). While it is not proposed to detail the full BNIM panel analysis process in this paper, the panel used in the wider study drew upon professionals in the field of child sexual abuse advocacy, therapy, treatment and policy to examine the data from one whole transcript and imagine what that adult's experience was like for them. The panel seeks to re-live and not re-interpret the data and by doing so provides the researcher with alternative view points and a means of breaking down bias. While the full BNIM method of data collection and analysis was used with one interview all interviews were subsequently analysed using a broader thematic analysis method (Bryman, 2008). Interviews were audio recorded, with consent, and transcribed personally by the researcher. Transcripts were then subjected to line-by-line thematic analysis using NVivo 10 software. Open coding was conducted resulting in 61 open codes. Similarities and differences, use of specific language and phrases and common categories and typologies were then explored using deeper, axial coding (Ryan and Bernard, 2003). Themes and notes from the panel process were used during this coding process also. Six over-arching themes were identified. 


\section{A Brief Sample of the Findings:}

The use of a gatekeeping organisation who could offer follow up supports to participants provided a means of accessing what can be, for all the reasons discussed above, a hard to reach population. The use of a BNIM methodology presented a platform upon which such participants could share their voices and experiences, in their own words and in a way that felt relevant to them at that time. Disclosure is a fluid and inter-relational process and while the facts don't change, a person's ability to make meaning of their experiences will develop over their life course. The wider study had three main aims: 1) to examine what the facilitators and barriers are for adults disclosing to social work services; 2) to examine if services take account of the specific needs of adults who have experienced abuse in their childhoods and; 3) to present policy and practice recommendations informed by the findings of this study. While it is not feasible in this paper to discuss the entire findings, it is interesting that the adults interviewed did highlight an awareness of the various barriers that sought to silence them. Data from the wider study identified that the system itself acts as a barrier for those who wish to come forward or who find themselves obligated to engaged with social work services. The experiences shared by the adult participants showed that we can trace the potentially silencing impact of policy and guidance at a macro level down through local services and staff to impact not only on the adult in their microsystem (their inner most social circles) but also on a very basic, ontogenic level, their very core. The narratives highlighted the importance of social workers understanding the adult as an individual affected by childhood abuse but also a need to understand the possible effects of that abuse and the difficulties regarding disclosure:

People ... ya know... some people don't even realise... what way sexual abuse effects them like ya know, the way they are, their personality like ya know. So, I just think that there should be basic consideration to, at least try to imagine ... how ... that person is feeling coming to meet you... Are they nervous, are they anxious... (Alan)

Participants spoke about the personal barriers that kept them silent for so long; barriers which they had to overcome prior to engaging with social work services:

... I couldn't find the courage like, I threatened it long, many times like ya know that I'd go forward and just contact someone and just let them know that it's confidential like ya know just do it in some way that he's out of harm's way, but I didn't like. (Alan)

Alan continues with some advice for those professionals engaging with adults impacted by abuse. In this statement he succinctly emphasises the impact of multiple barriers and what it takes for some individuals to come forward and disclose: 
'Consider that those, the people you're going to meet are probably all that week leading up to it thinking about it, going through it, re-living what's happened to them, ya know, going back to a place where they don't necessarily want to be, want to visit, like ya know. All these things like that have to be taken in to account.' (Alan)

Echoing the international literature, the participants also strongly identified family dynamics as barriers to disclosure. Some adults expressed fear about what might happen to their family once they disclosed; others were fearful about not being believed. Patrick experienced abuse at the hands of his sisters and here he identifies why intra-familiar abuse can present such an extra barrier to disclosure:

... one of the reasons I didn't come forward with this information was because of who they are... they weren't random strangers on the street... d'you know what I mean ... (Patrick)

Signifying the potential layers of silence and obstacles to sharing one's story, the adults identified barriers on personal, familial but also societal levels. While not spoken about in terms of social construction or societal discourse the participants show a strong awareness of such features. Tony puts this very directly:

... the first thing's doubt, do people actually believe what you're saying...' (Tony)

Given that the overarching focus of the wider study was to examine interactions with social work services the participants also demonstrated a strong understanding of the socio-legal environment in which their disclosure sat. One of the key problematic issues regarding social work assessments of retrospective disclosures is the lack of a clear legal mandate and framework (Mooney, 2018). The adults' awareness of this legal ambiguity demonstrates the ability of macro level factors to have quite a profound effect on a person's individual experience of disclosure. Patrick identifies an awareness of the legal complexity of making a disclosure to social work services and of this being somehow in competition with his lived experience:

I understand for them it's all allegations up to a point but for me it's clearly not because it's my lived experience and I know it's real... (Patrick)

This paper highlights the importance of not just being able to tell one's story, but also the reaction to that story once told. In terms of the interaction with social work practitioners, all of the participants explained how many of the responses they received served to harm or silence them further:

... at the end the little girl at the end who was taking the notes said, 'that was a lot of talk' she said. And that was kind of hurtful. She said, 'that was a lot of talk' and 
when I went out [Therapist] said to me 'that was tough. (David)

Jane notes the importance of her own personal strength and resilience in continuing to disclose and go through the process in spite of such responses. She does note however that not everyone may have such resources:

... very ahm worrying, I mean I'm lucky enough that I've got a good support and I've managed to, you know I think I've got fairly ok head on my shoulders to get through but fucking hell... if I had been, if I had had one foot ... on the side of a cliff and ended up in front of that [social work process].... Not them people, but that process... (Breath intake) and I relied on it... yeah.... Both feet over the cliff. (Jane)

\section{Limitations}

This paper, and the wider study, emphasise the important point that 'studies conducted among adult survivors have offered insight that can underscore the different layers of influence on CSA disclosure, from individual to collective dynamics (Collin-Vézina et al, 2015, p.126). It should be anticipated when researching sensitive issues that ethical issues may arise and can limit the use of the methodology. Given the sensitive nature of the wider research, in addition to the researcher's social work training, STORM suicide assessment training was also attained in order to allow the researcher to provide support during a research interview should a crisis situation become apparent such as suicidal intent or ideation. BNIM urges the interviewer not to prompt, respond or direct the interviewee and so such a scenario would require a break in methodological protocol for the safety and well-being of the participant. While this did not occur among the wider sample, a situation did arise whereby one participant chose to provide a narrative that did not directly relate to the proposed SQUIN and instead focused primarily on their experience of abuse during childhood. Given the control afforded, the methodology allows for this, the participant can share what they wish and while not asked directly about their experiences of abuse they were free to discuss this if they wished. In this particular interview, due to ethical concerns, the researcher broke with BNIM protocol and did guide the participant through the interview, affirming certain statements, acknowledging discomfort and providing a supportive space. The author also built private therapeutic supervision sessions into the design of the research. These sessions were conducted during the data collect and analysis stages and were a means of minimising any potential vicarious trauma.

As discussed, a gate-keeper was used in order to recruit the participants for the study. While this brought its own limitations in that the sample potentially had, via therapy and advocacy input, a means of discussing the topic that affected members 
of the public may not have had. Kennan, Fives and Canavan (2012) also warn that 'reliance on service providers as gatekeepers may further exacerbate power inequalities between service providers and disadvantaged and/or marginalized clients' (2012, p279). While ethical constraints within this sensitive area of research required the use of gate-keeper organisation to ensure the safety and well-being of the participants, the potential resultant power imbalance further emphasised the importance of using a methodology that provided power, control and choice to the individual participants.

\section{Conclusion}

This paper presents some of the ethical and methodological dilemmas that may manifest when conducting research with adults who have experienced sexual abuse in childhood. The paper demonstrates that such a population is predominantly hidden or silenced for a number of reasons, not least the traumatic and inter-personal effects of the abuse itself. The paper however focusses on two specific factors that can silence, or cast shadows over those effected, leaving them voiceless within the dominant discourse. The first of these is the socially constructed nature of our responses and attitudes towards child sexual abuse in general. We see how this has followed a specific trajectory in Ireland but has also been influenced more generally by what Olafson et al termed the 'emergence and regression' of our knowledge and awareness of child sexual abuse. Once this barrier of social stigma, societal shame and mistrust of authorities has been overcome and individual must then surmount the personal and interpersonal barriers that are created as a consequence of the abuse but also as a product of the process of disclosure. The paper discussed the many barriers to disclosure, as established in the research literature, and which are echoed in the voices of the participants of the author's own research, which forms the basis of this paper.

The paper then highlights the author's rationale for selecting Biographical Narrative Interviewing Methodology as a method of addressing such structural and personal barriers. Teram et al (1999) notes that 'modes of inquiry that allow clients to determine the level and timing of disclosure are likely to encourage them to share their history of abuse, or how this history shapes their feelings and needs...' (1999, p.94). The power and control of the adult participant is key in the BNIM process in that the initial SQUIN affords the participant the control over what is discussed and how it is discussed. The lack of prompts or probing allows a narrative to be formed that is a product of the participant's decisions. We can see from a small sample of the findings that the adults who participated were acutely aware of the multiple barriers they faced in respect of coming forward to share their stories. The data identify barriers within all of the individual's socio-ecological layers; micro, 
meso, exo and macro (Bronfenbrenner, 1979). While there are some limitations to the methodology the paper makes a strong, evidenced based argument for use of narrative approaches to access and research with hard to reach populations and sensitive subjects. The element of power is considered in such methodologies and this is particularly key when examining the issue of childhood sexual abuse given the power dynamics that may be at play.

\section{References}

Alaggia, R. (2004) Many ways of telling: expanding conceptualizations of child sexual abuse disclosure. Child Abuse and Neglect, 28, 1213-1227

Alaggia, R. (2005) Disclosing the trauma of child sexual abuse: A gender analysis. Journal of Trauma and Loss, 10, 5, 453-470

Alaggia, R., Collin-Vézina, D., and Lateef, R. (2017) Facilitators and barriers to child sexual abuse (CSA) Disclosure: A research update (2000-2016) Trauma, Violence and Abuse, 1-24

Alaggia, R, and Kirshenbaum, S. (2005) Speaking the unspeakable: Examining the impact of family dynamics on child sexual abuse disclosures. Families in Society, 86, 2, 227-234

Anderson, G. (2016) The Continuum of Disclosure: Exploring Factors Predicting Tentative Disclosure of Child Sexual Abuse Allegations During Forensic Interviews and the Implications for Practice, Policy, and Future Research. Journal of Child Sexual Abuse, 25, $4,382-402$

Azzopardi, C., Alaggia, R., and Fallon, B. (2017) From Freud to feminism: Gendered constructions of blame across theories of child sexual abuse. Journal of Child Sexual Abuse, DOI: 10.1080/10538712.2017.1390717

Barrett, A., Kamiya, Y., and O'Sullivan, V. (2014) Childhood sexual abuse and later-life economic consequences. Journal of Behavioral and Experimental Economics, 53, 10-16

Bradley, C. (2014) Reproducing Stigma: Narratives of single women's pregnancy and motherhood in Ireland 1990-2010. PhD Thesis, National University of Ireland, Galway

Bronfenbrenner, U. (1979) The Ecology of Human Development: Experiments by nature and design. Cambridge MA: Harvard University Press

Browne, A., and Finkelhor, D. (1986) Impact of child sexual abuse: A review of the research. Psychological Bulletin, 99, 1, 66-77

Bryman, A. (2008) Social Research Methods. (3rd ed) Oxford, Oxford University Press

Buckley, S.A. (2013) The Cruelty Man: Child welfare, the NSPCC and the State in Ireland, 18891956. Manchester : Manchester University Press

Campbell, R., Greeson, M., Fehler-Cabral, G., and Kennedy, A. (2015) Pathways to help: Adolescent sexual assault victims' disclosure and help-seeking experiences. Violence Against Women, 21, 7, 824-847

Collin-Vézina, D., Daigneault, I., and Hébert, M. (2013) Lessons learned from child sexual abuse research: prevalence, outcomes and preventative strategies. Child and Adolescent 
Psychiatry and Mental Health, 7, 22

Collin-Vézina, D., Sablonni, D. L., Palmer, A. M., and Milne, L. (2015) A preliminary mapping of individual, relational, and social factors that impede disclosure of childhood sexual abuse. Child Abuse and Neglect, 43, 123-134

Corbally, M., and O'Neill, C. (2014) An introduction to the biographical narrative interpretive method. Nurse Res. 21, 5, 34-9

Denov, M. (2004) The long-term effects of child sexual abuse by female perpetrators: A qualitative study of male and female victims. Journal of Interpersonal Violence, 19, $1137-1156$

Department of Children and Youth Affairs (2017) Children First: National guidance for the protection and welfare of children. Dublin: Government Publications

Department of Health and Children (2008) National Review of Compliance with Children First: National Guidelines for the Protection and Welfare of Children. Dublin: The Stationary Office

Dorahy, M., and Clearwater, K. (2012) Shame and guilt in men exposed to childhood sexual abuse: A qualitative investigation. Journal of Child Sexual Abuse, 21, 155-175

Douglas, E., and Finkelhor, D. (2005) Childhood Sexual Abuse Fact Sheet. Crimes Against Children Research Centre, May 2005

Finkelhor, D. (1994) The International Epidemiology of Child Sexual Abuse. Child Abuse and Neglect, 18, 5, 409-417

Ferguson, H., and Kenny, P. (Eds.) (1995) On Behalf of the Child: Child welfare, child protection and the Child Care Act 1991. Dublin: A \& A Farmer

Foucault, M. (1976) The History of Sexuality, Vol. 1. Translation R. Hurley. (1998) Harmondsworth: Penguin

Fraser, H. (2004) Doing narrative research: Analysing personal stories line by line. Qualitative Social Work, 3, 2, 179-201

Freeman, K., and Morris, T., (2001) A review of conceptual models explaining the effects of child sexual abuse. Aggression and Violent Behaviour, 6, 357-373

Health Information and Quality Authority (2016) Overview of 2016 HIQA Regulation of Social Care and Healthcare Services (Report April 2017), Retrieved from HIQA website: www.hiqa.ie

Hébert, M., Tourigny, M., Cyr, M., McDuff, P., and Joly, J. (2009) Prevalence of childhood sexual abuse and timing of disclosure in a representative sample of adults from Quebec. The Canadian Journal of Psychiatry, 54, 631-636

Hooper, C., and Warwick, I. (2006) Gender and the politics of service provision for adults with a history of childhood sexual abuse. Critical Social Policy, 26, 2, 467-479

Hunter, S. (2010) Evolving narratives about childhood sexual abuse: Challenging the dominance of the victim and survivor paradigm. The Australian and New Zealand Journal of Family Therapy, 31, 2, 176-190

Hunter, S. (2011) Disclosure of child sexual abuse as a life-long process: Implications for health professionals. The Australian and New Zealand Journal of Family Therapy, 32, 2 , 159-172

Jones, D. P. H. (2000) Editorial: Disclosure of child sexual abuse. Child Abuse \& Neglect, 24, 2, 269-271 
Jones, K. (2003) The turn to a narrative knowing of persons: One method explored. Nursing Times Research, 8, 1

Jonzon, E. and Lindblad, F. (2004) Disclosure, reactions, and social support: Findings from a sample of adult victims of child sexual abuse. Child Maltreatment, 9, 2, 190-200

Kennan, D., Fives, A., and Canavan, J. (2012) Accessing a hard to reach population:Reflections on research with young carers in Ireland. Child and Family Social Work, 17, 275-283

Riessman, C. K., \& Quinney, L. (2005) Narrative in social work: A critical review. Qualitative Social Work, 4, 4, 391-412

Lalor, K. (1998) Child sexual abuse in Ireland: An historical and anthropological note. Irish Journal of Applied Social Studies, 1, 1, 37-54

Leventhal, J. (2001) A decline in substantiated cases of child sexual abuse in the United States: good news or false hope? Child Abuse and Neglect, 25, 1137-1138

Masson, J. M. (1984) The assault on truth: Freud's suppression of the seduction theory. New York: Farrar, Strauss, and Giroux

McElvaney, R. (2013) Disclosure of child sexual abuse: delays, Non-disclosure and partial disclosure. What the research tells us and implications for practice. Child Abuse Review, 24, 159-169

McGee, H., Garavan, R., de Barra, M., Byrne, J., and Conroy, R. (2002) The SAVI Report: Sexual Abuse and Violence in Ireland. Dublin: The Liffey Press

McGee, H., Garavan, R., Leigh, C., Ellis, C., and Conroy, R. (2005) SAVI Revisited: Long term effects of disclosure of sexual abuse in a confidential research interview. Dublin, Dublin Rape Crisis Centre

McNulty, C., and Wardle, J. (1994) Adult disclosure of sexual abuse: A primary cause of psychological distress? Child Abuse and Neglect, 18, 7, 549-555

Mian, M., Wehrspann, W., Klajner-Diamond, H., Labaron, D., and Winder, C. (1986) Review of 125 children 6 years of age or under who were sexually abused. Child Abuse and Neglect, 4, 223-229

Mooney, J. (2014) Adult disclosures of childhood sexual abuse to child protection services: Current issues in social work practice. The Irish Social Worker, Spring/Summer 2014, 9-13

Mooney, J. (2018) Adult disclosures of childhood sexual abuse and section 3 of the Child Care Act 1991: Past offences, current risk, Child Care in Practice, DOI: 10.1080/13575279.2017.1347145

Murray, S.L. (1994) Storytelling in close relationships: The construction of confidence. Personality and Social Psychology Bulletin, 20, 650-663

Office of the Ombudsman (2017) Taking Stock: An investigation by the Ombudsman into complaint handling and issues identified in complaints made about the Child and Family Agency (Tusla). Dublin : Office of the Ombudsman

Olafson, E., Corwin, D. and Summit, R. (1993) Modern history of child sexual abuse awareness: Cycles of discovery and suppression. Child Abuse and Neglect, 17, 7-24

Ombudsman for Children's Office (2010) A Report based on an Investigation into the Implementation of Children First: National Guidelines for the Protection and Welfare of Children. Dublin: Ombudsman for Children's Office 
O'Sullivan, E. (2002) 'This otherwise delicate subject': Child sexual abuse in early twentieth century . in P. O'Mahony, (Ed.) Criminal Justice in Ireland Dublin: Institute of Public Administration,

Potts, K. and Brown, L. (2003) Becoming an anti-oppressive researcher. in L. Brown and S. Strega (Eds.) Research as Resistance, Critical, indigenous and anti-oppressive approaches. Toronto: Canadian Scholars' Press (, pp. 255-286)

Reitsema. A.M, and Grietens, H. (2016) Is anybody listening? The literature on the dialogical process of child sexual abuse disclosure reviewed. Trauma, Violence and Abuse, 17, 3, 330-340

RTE's This Week (2017), 30th July 2017. Accessed online at: http://www.rte.ie/radio/utils/ radioplayer/rteradioweb.html\#!rii=b9_21210480_0_

Rush, F. (1996) The Freudian coverup. Feminism and Psychology, 6, 261-276

Ryan, G., and Bernard, R. (2003) Techniques to identify themes. Field Methods, 15, 1, 85 -109

Tener and Murphy (2015) Adult disclosure of child sexual abuse: a literature review. Trauma, Violence and Abuse, 16, 4, 391-400

Teram, E., Schachter, C. L., and Stalker, C. A. (1999) Opening the doors to disclosure: Childhood sexual abuse survivors reflect on telling physical therapists about their trauma. Physiotherapy, 85, 2, 88-97

Tew, J. (2006) Understanding power and powerlessness. Towards a framework for emancipatory practice in social work. Journal of Social Work 6:1, 33-51

Ullman, S., Ming-Foynes, M., and Tang, S., S-S. (2010) Benefits and barriers to disclosing sexual trauma: A contextual approach. Journal of Trauma and Dissociation, 11, 2, 127-133

Wengraf, T. (2001) Qualitative Research Interviewing: Biographic narrative and semi-structured methods. London: Sage

Wengraf, T. (2017) BNIM -Interview - 2-day Training Brochure. Training Course, London, January 2017 